\title{
Surgical outcomes are hampered after endoscopic ultrasonography-guided ethanol lavage and/or Taxol injection in cystic lesions of the pancreas
}

\author{
Seong-Ryong Kim', Song Cheol Kim², Ki Byung Song ${ }^{2}$, Kwang-Min Park², Dae Wook Hwang ${ }^{2}$, \\ Jae Hoon Lee ${ }^{2}$, Sang Hyun Shin ${ }^{3}$, Bong Jun Kwak², Young-Joo Lee ${ }^{2}$ \\ 'Division of Hepatobiliary and Pancreatic Surgery, Department of Surgery, Dongguk University Ilsan Hospital, Goyang, Korea, \\ ${ }^{2}$ Division of Hepatobiliary and Pancreatic Surgery, Department of Surgery, Asan Medical Center, University of Ulsan College of Medicine, Seoul, Korea, \\ ${ }^{3}$ Division of Hepatobiliary and Pancreatic Surgery, Department of Surgery, Samsung Medical Center, \\ Sungkyunkwan University School of Medicine, Seoul, Korea
}

\begin{abstract}
Backgrounds/Aims: Endoscopic ultrasonography-guided ethanol lavage and Taxol injection (EUS-ELTI) for pancreatic cystic lesions have been recently performed in some medical centers. The aim of this study was to optimize patient selection and analyze outcomes of patients who underwent surgeries after EUS-ELTI for pancreatic cystic lesions.

Methods: Among 310 patients who underwent EUS-ELTI between January 2007 and December 2014, 23 underwent surgeries after EUS-ELTI owing to incomplete treatment and/or adverse events. Surgical outcomes of patients who underwent surgeries after EUSELTI were evaluated. Clinical outcomes of patients who underwent surgeries after EUS-ELTI were then retrospectively compared with those of patients who underwent upfront surgery for left-sided pancreatic lesions without an EUS-ELTI procedure.

Results: The pathology revealed degenerated cysts in 12 patients, mucinous cyst neoplasms in five, neuroendocrine tumors in two, intraductal papillary mucinous neoplasm (IPMN) in one, solid pseudopapillary tumor in one, pancreatic ductal adenocarcinoma arising from an IPMN in one, and hepatoid carcinoma in one. Twelve patients underwent laparoscopic distal pancreatectomy and five patients underwent open distal pancreatectomy. When clinical outcomes were retrospectively compared between patients who underwent laparoscopic distal pancreatectomy after EUS-ELTI and those who did not receive an EUS-ELTI procedure, the spleen-preserving rate was $0 \%$ in the EUS-ELTI group and $61.7 \%(365 / 592)$ in the control group $(p<0.001)$.
\end{abstract}

Conclusions: Surgical outcomes are compromised after EUS-ELTI for cystic tumor of the pancreas. Further studies are needed to investigate the efficacy and safety of the EUS-ELTI procedure.

Key Words: Endoscopic ultrasonography-guided ethanol lavage and Taxol injection; Minimally invasive surgery; Pancreatic cystic neoplasm

Received: April 17, 2021, Revised: June 26, 2021

Accepted: June 28, 2021

Corresponding author: Song Cheol Kim

Division of Hepatobiliary and Pancreatic Surgery, Department of Surgery, Asan Medical Center, University of Ulsan College of Medicine, 88 Olympic-ro 43-gil, Songpa-gu, Seoul 05505, Korea

Tel: +82-2-3010-3936, Fax:+82-2-3010-6701, E-mail: drksc@amc.seoul.kr ORCID: https://orcid.org/0000-0003-4552-4169

Copyright (C) The Korean Association of Hepato-Biliary-Pancreatic Surgery This is an Open Access article distributed under the terms of the Creative Commons Attribution Non-Commercial License (http://creativecommons.org/licenses/by-nc/4.0) which non-commercial use, distribution, and reproduction in any medium, provided the original permits unrestricted work is properly cited.

\section{INTRODUCTION}

With widespread use of imaging modalities, cystic tumors of the pancreas are now detected more frequently and incidentally [1]. Surgical resection is the treatment of choice for cystic tumors due to difficulty in differentiating between malignant and benign tumors at the initial diagnosis and the inherent malignant potential of some cystic tumors. When a large cystic tumor is detected at the initial imaging evaluation or a size increase during the follow-up and suspicious findings of malignancy are detected, patients usually opt for surgical resection of the cystic lesion. However, for elderly patients and those who 
have numerous underlying conditions or ambiguous-sized cystic tumors, it is difficult to choose surgical resection as the initial treatment modality. Recently, endoscopic ultrasonography-guided ethanol lavage and Taxol injection (EUS-ELTI) for benign and low-grade malignant pancreatic cystic lesions have been performed in some medical centers and highlighted in gastroenterology journals [1-6]. This procedure has merits, including being a minimally invasive procedure for patients with severe comorbidity and helping increase the possibility of preserving the pancreatic parenchyma. Previous studies have concluded that EUS-ELTI is safe and feasible. For some cases, it may lead to complete resolution of the disease [7]. Furthermore, some endoscopists have expanded the use of EUS-ELTI to the treatment of neuroendocrine tumors of the pancreas $[8,9]$.

However, when adverse events occur after EUS-ELTI or when treatment results are unsatisfactory, patients are required to have a repeat procedure or undergo a surgical resection of the lesion. Although many reports on EUS-ELTI in pancreatic cystic tumors have shown various results, surgical outcomes of patients who undergo surgeries after failures of EUS-ELTI have not been reported yet. Recently, minimally invasive pancreatic surgery has been increasingly accepted, especially in left-sided pancreatic resection, showing better results in terms of safety, hospital stay, and organ preservation than conventional open surgery.

In general, surgeries after inflammation-inducing procedures are very complicated, resulting in various adverse events and unexpected damage to patients. Acute pancreatitis or an inflammatory process after the EUS-ELTI procedure requires extensive resection of surrounding organs which may result in unexpected surgical adverse events. Assuming surgical outcomes of patients who undergo EUS-ELTI as the first-line treatment of pancreatic cysts are much worse than those of patients who initially undergo surgeries, it is reasonable to establish a guideline for performing EUS-ELTI based on both tumor biology and surgical outcomes of these patients.

With this assumption, the objective of this study was to retrospectively compare surgical outcomes of patients after an EUS-ELTI procedure for pancreatic cystic tumors with those of patients who underwent upfront surgery for left-sided pancreatic lesions without an EUS-ELTI procedure during the same period. Comparisons for pancreatic head lesions were not performed in this study. This is because laparoscopic surgery for pancreatic head lesions is not yet accepted as a standard procedure.

\section{MATERIALS AND METHODS}

Indications for EUS-ELTI were as follows: (1) unilocular or oligolocular cystic lesions (defined as having two to six locules within a cyst), (2) indeterminate cystic lesions in which EUSfine needle aspiration was indicated for obtaining additional information, and/or (3) cystic lesions that increased in size during the observation period [1,7].

A total of 310 patients underwent EUS-ELTI between January 2007 and December 2014 at Asan Medical Center in South Korea. All EUS procedures were performed by experienced endosonographers and cyst fluid aspiration with ethanol lavage and/or Taxol injection procedures performed according to the regular treatment protocol $[1,10]$. These 310 patients were followed for a median time of 48 months (interquartile range [IQR], 37.48). Among them, 209 patients had no evidence of disease recurrence over the median follow-up period (49 of 209 patients were lost during follow-up) and 101 patients required additional treatments. Of these 101 patients, 63 were lost during follow-up and 15 underwent EUS-ELTI again without a recurrence of the disease. Twenty-three patients underwent surgery after EUS-ELTI owing to incomplete treatment in the initial trial or repeat trial of EUS-ELTI $(n=18)$ or adverse events after EUS-ELTI $(n=5)$. Data of 23 patients who underwent surgeries after EUS-ELTI were analyzed (Fig. 1). Regarding locations of lesions, they were located on the pancreatic head in 7 patients, the pancreatic body in 5 , and the pancreatic tail in 8 (Fig. 2). Clinical outcomes in terms of hospital stay, adverse events, operation time, and spleen preservation rate were also compared between patients who underwent laparoscopic distal pancreatectomy (LDP) as an initial treatment and those who underwent LDP after EUS-ELTI.

All statistical analyses were performed with IBM SPSS ver-

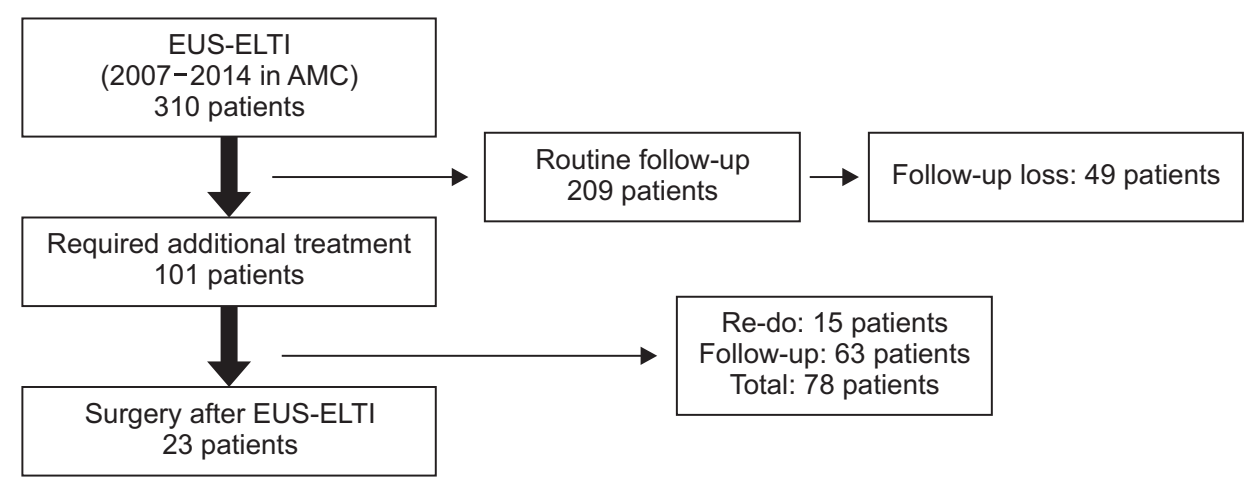

Fig. 1. Study flow diagram. EUS-ELTI, Endoscopic ultrasonography-guided ethanol lavage and Taxol injection; AMC, Asan Medical Center. 


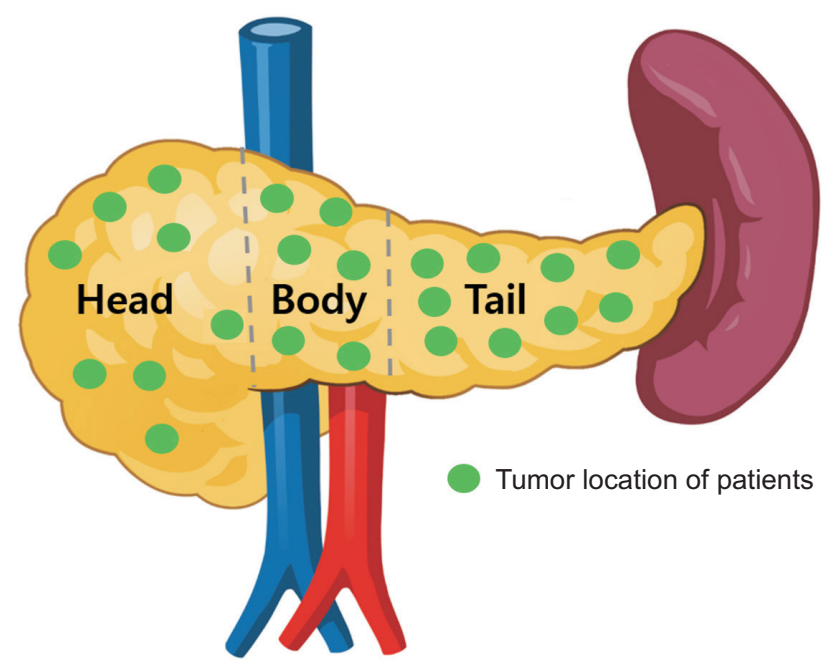

Fig. 2. Distribution of tumor location.

Table 1. Patient demographics and perioperative outcomes

\begin{tabular}{lccc}
\hline \multicolumn{1}{c}{ Variable } & $\begin{array}{c}\text { Patient } \\
(\mathrm{n}=23)\end{array}$ & $\begin{array}{c}\text { Head } \\
(\mathrm{n}=8)\end{array}$ & $\begin{array}{c}\text { Body/tail } \\
(\mathrm{n}=15)\end{array}$ \\
\hline Sex (male : female) & $10: 13$ & $5: 3$ & $5: 10$ \\
Median age $(\mathrm{yr})$ & $60(24)$ & $62(24)$ & $60(18)$ \\
Body mass index $\left(\mathrm{kg} / \mathrm{m}^{2}\right)$ & $23.1(4.45)$ & $23.5(3.25)$ & $22.8(4.45)$ \\
Mean operation time $(\mathrm{min})$ & 279.4 & 361.7 & 226.1 \\
Mean hospital stay (day) & 14.0 & 18.8 & 11.1 \\
$\begin{array}{c}\text { Clinically relevant POPF } \\
\text { (ISGPF grade B or C) }\end{array}$ & $6(26.1)$ & $2(25.0)$ & $4(26.7)$ \\
\hline
\end{tabular}

Values are presented as number only, median (interquartile range), or number (\%).

POPF, postoperative pancreatic fistula; ISGPF, International Society Grading for Pancreatic Fistula.

sion 18.0 (IBM Corp., Armonk, NY, USA). Categorical variables were analyzed using either the chi-square test or Fisher exact test, where appropriate. Parametric variables were analyzed using the Mann-Whitney test. A p-value $<0.05$ was considered statistically significant. This study was conducted in compliance with ethical principles of the Declaration of Helsinki. The study protocol was approved by the Institutional Review Board of the Asan Medical Center (IRB no. S2017-1136-0001). All patients provided written informed consent. All methods were performed in accordance with relevant guidelines and regulations.

\section{RESULTS}

\section{Demographics}

The median age of the 23 patients was 60 years (IQR: 24). Of these patients, 13 (56.5\%) were female. The median body mass index was $23.1 \mathrm{~kg} / \mathrm{m}^{2}$ (IQR: 4.45) (Table 1). Fifteen patients
Table 2. Reasons for surgery

\begin{tabular}{lccc}
\hline \multicolumn{1}{c}{ Variable } & $\begin{array}{c}\text { Patient } \\
(\mathrm{n}=23)\end{array}$ & $\begin{array}{c}\text { Head } \\
(\mathrm{n}=8)\end{array}$ & $\begin{array}{c}\text { Body/tail } \\
(\mathrm{n}=15)\end{array}$ \\
\hline Size increase & 15 & 4 & 11 \\
Fluid collection & 1 & 0 & 1 \\
Suspicious malignancy & 3 & 2 & 1 \\
Massive portal vein thrombosis & 1 & 1 & 0 \\
Hematochezia & 1 & 0 & 1 \\
Abdominal pain aggravation & 1 & 1 & 0 \\
Combine operation & 1 & 0 & 1 \\
\hline
\end{tabular}

Values are presented as number.

Table 3. Locational distribution

\begin{tabular}{ccccc}
$\begin{array}{c}\text { The } \\
\text { location }\end{array}$ & $\begin{array}{c}\text { EUS-ELTI } \\
(\mathrm{n}=310)\end{array}$ & $\begin{array}{c}\text { Surgery } \\
(\mathrm{n}=23)\end{array}$ & $\begin{array}{c}\text { Percentage } \\
\text { of surgery } \\
(\%)\end{array}$ & $p$-value \\
\hline Head & 111 & 8 & 7.2 & 0.572 \\
Body & 108 & 6 & 5.6 & \\
Tail & 81 & 9 & 11.1 & \\
\hline
\end{tabular}

Values are presented as number.

EUS-ELTI, endoscopic ultrasonography-guided ethanol lavage and Taxol injection.

received EUS-ELTI more than twice. Patients had various reasons for surgery: a size increase of the pancreatic lesion after EUS-ELTI in 15 patients, suspected malignancy in three patients, severe fluid collection around the pancreas after the procedure in one patient, massive portal vein thrombosis after EUS-ELTI with a cystic lesion in the pancreatic head in one patient, hematochezia after the procedure in one patient, progressive abdominal pain in one patient, and combined gastric surgery in one patient (Table 2).

The relation between tumor location and the rate of conversion to surgical treatment was analyzed. After EUS-ELTI, among those who underwent surgery, 8 of 111 patients (7.2\%) had lesions in the pancreatic head, 6 of 108 patients (5.6\%) had lesions in the pancreatic body, and 9 of 81 patients (11.1\%) had lesions in the pancreatic tail (Table 3). There was no statistically significant relationship between tumor location and conversion rate to surgical treatment $(p=0.572)$.

\section{Perioperative outcomes}

The mean operation time of the 23 patients was 279.4 minutes. The mean postoperative hospital stay was 14.0 days. Clinically relevant postoperative pancreatic fistulas (POPF) (grades $\mathrm{B}$ and $\mathrm{C}$ based on the International Society Grading for Pancreatic Fistula [ISGPF] system) occurred in six patients (26.1\%) (Table 1). Among 23 patients who underwent surgery, 18 had severe adhesions and inflammation. Among 17 patients with left-sided pancreatic lesions, 12 underwent LDP (11 with com- 
bined splenectomy and one with spleen preservation) and five patients underwent open distal pancreatectomy. One patient underwent internal drainage (cystojejunostomy was performed because of severe adhesion from a previous operation and/or procedure). Two years later, this patient underwent a pancreaticoduodenectomy because of abdominal pain induced by recurrent pancreatitis. Median time interval between EUS failure and surgery was 572 days (range, 91 to 1,792 days). The spleen preservation rate in patients with LDP after EUS-ELTI was $8.3 \%$ (1 of 12). All six patients who had lesions in the pancreatic head or uncinate process underwent an open pylorus-preserving pancreaticoduodenectomy (Table 4).

Pathologic outcomes of the 23 patients were reviewed. Twelve patients had pseudocysts or degenerated cysts. Five patients had mucinous cyst neoplasms and two patients had a neuroendocrine tumor. The remaining four patients each had an intraductal papillary mucinous neoplasm (IPMN), a solid pseudopapillary tumor, a pancreatic ductal adenocarcinoma arising from IPMN, and a hepatoid carcinoma (Table 5).

We had concerns about the higher conversion rate to open laparotomy, the higher rate of adverse events, and the lower rate

Table 4. Operation methods

\begin{tabular}{llccc}
\hline $\begin{array}{c}\text { Operation } \\
\text { (location) }\end{array}$ & $\begin{array}{c}\text { Lap/ } \\
\text { open }\end{array}$ & $\begin{array}{c}\text { No. of } \\
\text { patient } \\
(\mathrm{n}=23)\end{array}$ & $\begin{array}{c}\text { Laparoscopic } \\
\text { rate (\%) }\end{array}$ & $\begin{array}{c}\text { Spleen } \\
\text { preservation } \\
\text { (DP only) (\%) }\end{array}$ \\
\hline $\begin{array}{l}\text { DP } \\
\text { (body/tail) }\end{array}$ & Lap & $12(5 / 7)$ & $80(83.3 / 77.8)$ & $\begin{array}{c}1(8.3) \\
(1[20.0] / 0[0])\end{array}$ \\
& Open & $3(1 / 2)$ & & $1(33.3)$ \\
PD & Lap & 0 & 0 & $(1[100] / 0[0])$ \\
& Open & 6 & & \\
$\begin{array}{c}\text { Etc. } \\
\text { (CP and internal } \\
\text { drainage) }\end{array}$ & Open & 2 & 0 & \\
\hline
\end{tabular}

Lap, laparoscopic surgery; Open, open surgery; DP, distal pancreatectomy; $\mathrm{PD}$, pancreaticoduodenectomy; $\mathrm{CP}$, central pancreatectomy. of spleen preservation in patients who underwent laparoscopic surgical resection after EUS-ELTI, especially for pancreatic tail lesions. Thus, clinical outcomes were compared between patients who underwent LDP after EUS-ELTI and those who did not have the EUS-ELTI procedure for lesions in the pancreatic tail (control group, 592 patients) or the pancreatic body (146 patients) during the same period (Table 6, 7). Mean tumor size, patient age, and patient body mass index were comparable between the two groups.

No open distal pancreatic resection was performed in the control group. The spleen preservation rate was 0 (0 of 9) for patients in the EUS-ELTI group and 61.7 (365 of 592) for patients in the control group $(p<0.001)$ with pancreatic tail lesions. It was $20.0 \%$ ( 1 of 5 ) for patients in the EUS-ELTI group and $71.2 \%$ (104 of 146) for patients in the control group ( $p=$ $0.030)$ with pancreatic body lesions. Clinically relevant POPF (grades B and C based on the ISGPF system) occurred in three of nine patients $(33.3 \%)$ in the EUS-ELTI group and in 40 of 592 patients $(6.8 \%)$ in the control group $(p=0.025)$ with pancreatic tail lesions. The mean postoperative hospital stay was also significantly shorter in the control group than in the EUSELTI group (8.66 \pm 5.66 days vs. $13.56 \pm 7.20$ days, $p=0.032)$

Table 5. Pathologic outcomes

\begin{tabular}{lccc}
\hline \multicolumn{1}{c}{ Variable } & $\begin{array}{c}\text { Patient } \\
(\mathrm{n}=23)\end{array}$ & $\begin{array}{c}\text { Head } \\
(\mathrm{n}=8)\end{array}$ & $\begin{array}{c}\text { Body/tail } \\
(\mathrm{n}=15)\end{array}$ \\
\hline $\begin{array}{l}\text { Pseudocyst or degenerated cyst } \\
\text { Mucinous cyst neoplasm }\end{array}$ & 12 & 3 & 9 \\
Neuroendocrine tumor & 5 & 0 & 5 \\
Intraductal papillary & 2 & 2 & 0 \\
mucinous neoplasm (IPMN) & 1 & 0 & 1 \\
$\begin{array}{l}\text { Solid pseudopapillary tumor } \\
\text { Pancreas ductal }\end{array}$ & 1 & 1 & 0 \\
adenocarcinoma arising from IPMN & 1 & 1 & 0 \\
Hepatoid carcinoma & 1 & 1 & 0 \\
\hline
\end{tabular}

Values are presented as number.

Table 6. Comparison of tail lesions in laparoscopic distal pancreatectomy

\begin{tabular}{|c|c|c|c|}
\hline Variable & EUS-ELTI group $(n=9)$ & Control group $(n=592)$ & $p$-value \\
\hline Age (yr) & $54.0 \pm 13.04$ & $49.76 \pm 14.06$ & 0.422 \\
\hline Body mass index $\left(\mathrm{kg} / \mathrm{m}^{2}\right)$ & $24.53 \pm 1.97$ & $23.49 \pm 3.39$ & 0.170 \\
\hline Operation time (min) & $202.89 \pm 83.78$ & $187.73 \pm 62.52$ & 0.566 \\
\hline Tumor size $(\mathrm{cm})$ & $3.37 \pm 0.98$ & $3.66 \pm 2.26$ & 0.771 \\
\hline Postoperative hospital stay (day) & $13.56 \pm 7.20$ & $8.66 \pm 5.66$ & 0.032 \\
\hline Estimated blood loss (mL) & $456.43 \pm 674.61$ & $471.62 \pm 442.88$ & 0.305 \\
\hline Clinically relevant POPF (ISGPF grade B or C) & $3(33.3)$ & $40(6.8)$ & 0.025 \\
\hline Spleen preserving rate & $0(0)$ & $365(61.7)$ & $<0.001$ \\
\hline
\end{tabular}

Values are presented as mean \pm standard deviation or number (\%).

EUS-ELTI, endoscopic ultrasonography-guided ethanol lavage and Taxol injection; POPF, postoperative pancreatic fistula; ISGPF, International Society Grading for Pancreatic Fistula. 
Table 7. Comparison of body lesions in laparoscopic distal pancreatectomy

\begin{tabular}{lccc}
\hline \multicolumn{1}{c}{ Variable } & EUS-ELTI group $(\mathrm{n}=5)$ & Control group $(\mathrm{n}=146)$ & $p$-value \\
\hline Age $(\mathrm{yr})$ & $52.20 \pm 8.44$ & $51.93 \pm 12.60$ & $23.62 \pm 2.88$ \\
Body mass index $\left(\mathrm{kg} / \mathrm{m}^{2}\right)$ & $21.28 \pm 2.02$ & $222.55 \pm 65.35$ \\
Operation time $(\mathrm{min})$ & $251.40 \pm 72.04$ & $4.88 \pm 11.34$ & 0.059 \\
Tumor size $(\mathrm{cm})$ & $2.58 \pm 0.99$ & $8.61 \pm 4.72$ & 0.367 \\
Postoperative hospital stay (day) & $7.20 \pm 1.79$ & $461.19 \pm 427.79$ & 0.339 \\
Estimated blood loss (mL) & $336.82 \pm 156.25$ & $5(3.4)$ & 0.681 \\
Clinically relevant POPF (ISGPF grade B or C) & $1(20.0)$ & $104(71.2)$ \\
Spleen preserving rate & $1(20.0)$ & 0.186 \\
\hline
\end{tabular}

Values are presented as mean \pm standard deviation or number (\%).

EUS-ELTI, endoscopic ultrasonography-guided ethanol lavage and Taxol injection; POPF, postoperative pancreatic fistula; ISGPF, International Society Grading for Pancreatic Fistula.

with pancreatic tail lesions.

\section{DISCUSSION}

Recently, results of EUS-ELTI have been reported in many papers. Although many advantages are expected from this procedure, some procedure-related adverse events and postprocedural inflammatory processes including severe pancreatitis and severe inflammatory adhesions can develop on surrounding organs such as the stomach, colon, spleen, and blood vessels. These inflammatory processes can make subsequent surgeries after EUS-ELTI treatment difficult as they require extensive resection, thus disabling the preservation of the pancreatic parenchyma or adjacent organs. They can also make it difficult to perform a minimally invasive surgery. Advantages of minimally invasive laparoscopic pancreatectomy such as distal pancreatectomy and pancreaticoduodenectomy for benign and low-grade malignant diseases are well-known, including reports based on our center [11-13]. However, no study has reported surgical outcomes after failure of EUS-ELTI treatment.

Among the 23 patients who underwent surgical resection after EUS-ELTI treatment, 18 had operative findings of severe adhesion and inflammation. These findings made the operation difficult and caused many postoperative adverse events. In fact, almost all patients had procedure-induced pancreatitis. They underwent open surgery for treatment of lesions after EUS-ELTI. Although most (15/23) patients had surgery for increased lesion size, there was a pseudocyst or a degenerated cyst in $12 / 23$ from post-surgical pathologic analysis, confirming an inflammatory process inside or around the pancreatic cyst. Pancreatic cystic tumors are usually suitable for minimally invasive surgery irrespective of the location of the lesion. Among the 23 patients in this series, only $12(52.1 \%)$ could undergo laparoscopic surgery. In addition, all patients with pancreatic head lesions underwent an open pancreaticoduodenectomy. If patients chose surgical resection as the initial treatment for cystic tumors in the pancreas, they could undergo laparoscopic surgery in all cases irrespective of the location of the lesion.

When distal pancreatectomy is performed for benign cystic lesions, spleen preservation is very important for the patient. The prevalence of overwhelming post-splenectomy infections in adults has reported to be $0.8 \%-1.9 \%$ [14]. This rate is significant. It cannot be ignored, especially for old or immunocompromised patients. Many studies have reported that spleen preservation can decrease the rate of surgical site infection and improve short-term prognosis $[15,16]$. In the present study, among 15 patients who underwent distal pancreatectomy (open or laparoscopic), the spleen could be preserved in only two (13.3\%) patients. Among 12 patients who underwent LDP, the spleen could be preserved in only one $(8.3 \%)$ patient. In our data on laparoscopic pancreatectomy, the spleen could be preserved in $72.0 \%$ (587 of 815 ) of patients with benign pancreatic lesions. If patients chose a minimally invasive surgery as the initial treatment, the spleen could have a higher chance of preservation. The EUS-ELTI group of patients had significantly higher incidence of POPF after distal pancreatectomy (DP) than the upfront surgery group. POPF is one of the most serious complications after DP. It occurred in three of nine patients (33.3\%) in the EUS-ELTI group and in 40 of 592 patients $(6.8 \%)$ in the control group $(p=0.025)$ with pancreatic tail lesions. Because of inflammation occurring after a previous EUS-ELTI procedure, it was technically more difficult to treat the cut surface of the pancreas than for the group with an upfront surgery. For pancreas head lesions, some studies have reported that POPF is reduced when the pancreas is hardened due to chronic inflammation $[17,18]$. In this study, the EUSELTI procedure caused not only inflammation of the pancreas itself, but also increased difficulty of the operation and complications due to adhesions with adjacent organs caused by inflammation and formation of new collateral vessels.

Interestingly, in the present study, when lesions were in the far tail of the pancreas, the possibility of additional surgery was higher $(20.0 \%, 5$ of 20$)$ than that when lesions were in other locations of the pancreas. This might be due to the difficulty of accessing these lesions with EUS or the complicated 
vasculature around the splenic hilum, possibly resulting in incomplete EUS-ELTI. There are many important structures around the head of the pancreas, including the portal vein and superior mesenteric vessels. Injuring these vessels during the EUS-ELTI procedure can lead to severe adverse events. Massive portal vein thrombosis after EUS-ELTI has developed in one patient whose lesion is located in the pancreatic head, near the portal vein [19]. This study mainly compared lesions in the body and tail of the pancreas. Meaningful results are obtained since minimally invasive pancreatic resection of the pancreatic head lesion has not yet been accepted as a standard procedure. A comparative study of the lesions on the head of the pancreas needs to be conducted in the future.

In every case, EUS-ETLI eliminated pancreatic cystic lesions in about $90 \%$ of patients (only 23/224 with adequate follow-up needed surgery), saving many surgeries with their potential related adverse events. Regarding pathologic outcomes of 23 patients, two patients were diagnosed with cancer (8.7\%). Among these two patients, one patient underwent EUS-ELTI to treat a neuroendocrine tumor. The final pathology was hepatoid carcinoma. This patient is in an NED (no evidence of disease) condition who is being followed up through an outpatient clinic. The other patient underwent EUS-ELTI to treat IPMN. The final pathology was pancreatic ductal adenocarcinoma arising from IPMN with lymph node metastasis (One lymph node was reported as a metastatic lymph node among 11 harvested lymph nodes). At about five months after surgery, this patient showed elevated CA19-9 level on laboratory test. A computed tomography scan showed liver metastasis. The disease continued to worsen and he died at about one year after the surgery. Before performing EUS-ELTI, the initial diagnosis was always based on radiologic images. However, the initial diagnosis with radiologic images is not always precise. An increased risk of oncologic safety can occur when the lesion includes malignancies like in this study.

The most important limitation of this study was that the number of patients included in the study was relatively small (in a total of 23 patients, only 17 with lesion in the pancreatic body-tail were considered for the analysis). This might have altered clinical results. In recent years, there has been a progressive discard of the use of alcohol in the treatment of cystic lesions of the pancreas in favor of Taxol and other chemotherapies (Gentamicin for example) that seem to have the same effectiveness with fewer adverse events [20]. Data included in the analysis of this study corresponded to results of procedures performed from 2007 to 2014. If results of recent EUS treatments excluding ethanol lavage were included in the analysis, results of the study might be different. Thus, failing to exclude data containing ethanol lavage is another important limitation of this study.

In conclusion, an EUS-guided chemo-ablation procedure should be considered very cautiously because of its suboptimal clinical data, often inaccurate diagnosis, and compromised surgical outcomes. Although the present study has some limitations, including a small number of participants, this study is significant because it is the first report presenting surgical results after EUS-ELTI for physicians who are dealing with endoscopic treatment of pancreatic cystic neoplasms.

In conclusion, surgical outcomes can be compromised or suboptimal after EUS-ELTI in pancreatic cystic tumors. Further investigations are needed to determine the efficacy and safety of the EUS-ELTI in the era of minimally invasive surgery.

\section{FUNDING}

This study was supported by a grant (HI14C2640) of the Korean Health Technology R\&D Project funded by the Ministry of Health \& Welfare, Republic of Korea.

\section{CONFLICT OF INTEREST}

No potential conflict of interest relevant to this article was reported.

\section{ORCID}

Seong-Ryong Kim, https://orcid.org/0000-0002-7903-9797

Song Cheol Kim, https://orcid.org/0000-0003-4552-4169

Ki Byung Song, https://orcid.org/0000-0001-5422-5481

Kwang-Min Park, https://orcid.org/0000-0002-3059-3068

Dae Wook Hwang, https://orcid.org/0000-0002-1749-038X

Jae Hoon Lee, https://orcid.org/0000-0002-6170-8729

Sang Hyun Shin, https://orcid.org/0000-0002-2533-4491

Bong Jun Kwak, https://orcid.org/0000-0003-2409-9386

Young-Joo Lee, https://orcid.org/0000-0001-5352-8093

\section{AUTHOR CONTRIBUTIONS}

Conceptualization: SCK, KMP, YJL. Data curation: KBS, DWH, JHL. Methodology: SHS. Visualization: BJK. Writing original draft: SRK. Writing - review \& editing: SRK.

\section{REFERENCES}

1. Oh HC, Seo DW, Lee TY, Kim JY, Lee SS, Lee SK, et al. New treatment for cystic tumors of the pancreas: EUS-guided ethanol lavage with paclitaxel injection. Gastrointest Endosc 2008;67:636-642.

2. DeWitt J, McGreevy K, Schmidt CM, Brugge WR. EUS-guided ethanol versus saline solution lavage for pancreatic cysts: a randomized, double-blind study. Gastrointest Endosc 2009;70:710-723.

3. Goodman AJ, Gress FG. EUS-guided ethanol lavage for pancreatic cysts: is it ready for prime time? Gastrointest Endosc 2010;72:867-869.

4. Yoon WJ, Brugge WR. Endoscopic ultrasonography-guided tumor ablation. Gastrointest Endosc Clin N Am 2012;22:359-369, xi.

5. Zhang WY, Li ZS, Jin ZD. Endoscopic ultrasound-guided ethanol ab- 
lation therapy for tumors. World J Gastroenterol 2013;19:3397-3403.

6. Fabbri C, Luigiano C, Lisotti A, Cennamo V, Virgilio C, Caletti G, et al. Endoscopic ultrasound-guided treatments: are we getting evidence based: a systematic review. World J Gastroenterol 2014;20:8424-8448.

7. DeWitt J, DiMaio CJ, Brugge WR. Long-term follow-up of pancreatic cysts that resolve radiologically after EUS-guided ethanol ablation. Gastrointest Endosc 2010;72:862-866.

8. Kim J. Endoscopic ultrasound-guided treatment of pancreatic cystic and solid masses. Clin Endosc 2015;48:308-311.

9. Park DH, Choi JH, Oh D, Lee SS, Seo DW, Lee SK, et al. Endoscopic ultrasonography-guided ethanol ablation for small pancreatic neuroendocrine tumors: results of a pilot study. Clin Endosc 2015;48:158164.

10. Oh HC, Seo DW, Song TJ, Moon SH, Park DH, Soo Lee S, et al. Endoscopic ultrasonography-guided ethanol lavage with paclitaxel injection treats patients with pancreatic cysts. Gastroenterology 2011;140:172-179.

11. Song KB, Kim SC, Park JB, Kim YH, Jung YS, Kim MH, et al. Single-center experience of laparoscopic left pancreatic resection in 359 consecutive patients: changing the surgical paradigm of left pancreatic resection. Surg Endosc 2011;25:3364-3372.

12. Song KB, Kim SC, Hwang DW, Lee JH, Lee DJ, Lee JW, et al. Matched case-control analysis comparing laparoscopic and open pylorus-preserving pancreaticoduodenectomy in patients with periampullary tumors. Ann Surg 2015;262:146-155.

13. Shin SH, Kim SC, Song KB, Hwang DW, Lee JH, Park KM, et al. Ap- praisal of laparoscopic distal pancreatectomy for left-sided pancreatic cancer: a large volume cohort study of 152 consecutive patients. PLoS One 2016;11:e0163266.

14. Cullingford GL, Watkins DN, Watts AD, Mallon DF. Severe late postsplenectomy infection. Br J Surg 1991;78:716-721.

15. Shoup M, Brennan MF, McWhite K, Leung DH, Klimstra D, Conlon KC. The value of splenic preservation with distal pancreatectomy. Arch Surg 2002;137:164-168.

16. Carrère N, Abid S, Julio CH, Bloom E, Pradère B. Spleen-preserving distal pancreatectomy with excision of splenic artery and vein: a casematched comparison with conventional distal pancreatectomy with splenectomy. World J Surg 2007;31:375-382.

17. Casadei R, Ricci C, Taffurelli G, Pacilio CA, Di Marco M, Pagano N, et al. Prospective validation of a preoperative risk score model based on pancreatic texture to predict postoperative pancreatic fistula after pancreaticoduodenectomy. Int J Surg 2017;48:189-194.

18. Nahm CB, Connor SJ, Samra JS, Mittal A. Postoperative pancreatic fistula: a review of traditional and emerging concepts. Clin Exp Gastroenterol 2018;11:105-118.

19. Oh HC, Seo DW, Kim SC. Portal vein thrombosis after EUS-guided pancreatic cyst ablation. Dig Dis Sci 2012;57:1965-1967.

20. Teoh AY, Seo DW, Brugge W, Dewitt J, Kongkam P, Linghu E, et al. Position statement on EUS-guided ablation of pancreatic cystic neoplasms from an international expert panel. Endosc Int Open 2019;7:E1064-E1077. 